\title{
Israel Sanmartín y Sonia Gómez-Jordana, Temporalidad y contextos. La interdisciplinariedad a partir de la historia, el arte y la lingüística. Universidade de Santiago de Compostela: Santiago de Compostela, 2015, 815 págs.
}

El presente libro funciona, en buena medida, en continuidad con una obra anterior, tal y como afirman sus editores (p. 14). ${ }^{1}$ Esta continuidad se articula a través de un eje central: la creación de espacios interdisciplinares. El concepto de interdisciplinariedad, que en las últimas décadas parece ser un caballo de batalla para quienes se oponen a la "hiperespecialización" y al ensimismamiento académico, no suele estar bien definido. Se lanza como una suerte de declaración de intenciones, como un signo de una posición difusa. Este no es el caso en absoluto. Más bien, el libro parte de una posición teórica clara. Para los editores, no se trata de cargar contra las disciplinas existentes, de abogar por alguna de las disciplinas como fundacional, o de establecer una simple conversación entre especialistas de diversos ámbitos; sino de reconocer que las divisiones disciplinarias "son tanto o más campos institucionales y sociales que campos de saber" y que "los enunciados iniciales sobre cualquier temática [...] son universales, interdisciplinarios y comprensibles por todos" (p. 12) de manera que sea posible crear espacios en los que lo que prime sea la reflexión sobre estos conceptos y temáticas compartidos, reconociendo que es posible acercarse a ellos desde niveles muy diferentes. Es aquí, hasta donde yo alcanzo a entender, donde se sitúan los "espacios interdisciplinares" por los que el volumen aboga decididamente.

Ahora bien, ¿cuáles son estos conceptos o temáticas fundamentales que atraviesan toda disciplina? El propio título nos lo indica, las nociones de temporalidad y contextos, principalmente a través de la historia, el arte y la lingüísitica, pero no únicamente ya que también hay un espacio para la filosofía o la literatura. Como los editores indican "el Contexto y la Temporalidad [...] se pueden definir como una coordenada espaciotemporal imprescindible en toda investigación humanística" (p. 11). Es decir, estamos ante nociones que pertenecen a ese espacio primigenio (interdisciplinar) que ninguna investigación o reflexión, por mucho que este bien anclada en su disciplina, se puede permitir ignorar. Ahora bien, junto estas dos ideas (contexto y tiempo) encontramos otros temas u objetos fundamentales para las disciplinas humanísticas, que sirven para dividir el libro en seis grandes apartados: discursos, espacios, contextos, imagen, escritura y tiempo. Así, a través de estas nociones la lectura nos conduce por una amplia variedad de temas, que abarcan desde discursos políticos contemporáneos a la música medieval, pasando por el género gramatical, la sociolingüística, el cronista medieval Raúl Glaber, el 15-M, el reportaje, la teorización sobre la literatura, la propaganda visual y el nacionalismo, la geopolítica, o el Holocausto, entre otros muchos temas.

En la primera parte, dedicada al discurso, tiene un fuerte peso la lingüística, com no podía ser de otra manera. Empezando por un estudio del género gramatical en el español y el francés (Jean-Claude Anscombre), se abordan problemas como la aplicación de las teorías de la argumentación (Sonia Gómez-Jordana y Didier Tejedor de

\footnotetext{
${ }^{1}$ Israel Sanmartín, Patriia Calvo y Eduardo Rey Tristán (eds.), Historia(s), imagen(es), y lenguaje(s) en América Latina y Europa (Universidad de Santiago de Compostela: Santiago de Compostela, 2012).
} 
Felipe); los discursos de los niños víctimas del 11-M (Laurence Rouanne); la expresión verbal del tiempo en francés y español (Rania Talbi-Boulhais); el reportaje (Amelia Serraler Calvo) la llegada del francés a España (Antonio Gaspar Galán y Fidel Corcuera Manso) o los fundamentos teóricos del análisis del discurso francés (Fred Hailon), entre otros. Los aspectos políticos del discurso, en la teoría y en la práctica tienen un lugar central en esta sección. Pensemos, por ejemplo, en los trabajos de Sonia Gómez-Jordana y Didier Tejedor de Felipe quienes, en sendos capítulos ("Le discours présidentiel de fin d'année: un contexte festif pour implicites et présuppositions" y "Politique et linguistique: le temps d'un ethos", respectivamente) recurren a las ideas de Oswald Ducrot y Jean-Claude Anscombre, para aplicarlas a un discurso de fin de año de Nicolas Sarkozy y a un discurso pronunciado el 16 de septiembre de 1988 por Michel Rocard, miembro del Partido Socialista Francés.

Esta aproximación teórica consiste fundamentalmente en concebir el lenguaje como "une cristallisation de points de vue mettant en scène plusierurs discours dans un seul énoncé" (pp. 77-78). En paralelo con la teoría de los actos del habla, se conciben la enunciación como una acción realizada por un "locutor". 2 Ahora bien, no se asume un único sujeto en la producción del enunciado: "l'énoncé est le lieu où peuvent s'inscrire explicitemente ou implicitement différentes voix" (p. 102). Es decir, el locutor escoje un enunciado determinado para representar su voz, su ethos, pero en cada enunciado es posible inscribir diferentes puntos de vista. Esto lleva, en parte, a considerar toda enunciación como un argumento, ya que toda enunciación lleva implícita una serie de presuposiciones que le dan sentido. Así, la proposición "Pedro ha dejado de fumar" presupone que "Pedro fumaba" (ejemplo en la página 78). Partiendo de esto, S. GómezJordana y D.Tejedor nos descubren las presuposiciones e imagen que quieren transmitir N. Sarkozy y M. Rocard en sus discursos a través de un análisis lingüístico. Quizá se podría añadir que, como vienen recordando teóricos de la Escuela de Cambridge de historia intelectual, todo texto de pensamiento político está implicado en determinados debates y, por lo tanto, es un texto argumentativo. ${ }^{3}$

El análisis del discurso, desde otra perspectiva, también está presente en la aportacion de Fred Hailon ("Une linguistique de l'histoire: l'Analyse du Discours à la française"), quién nos introduce a una serie de autores (Louis Althusser, Jacques Lacan, Michel Pêcheux o Michel Foucault, entre otros) y un conjunto de conceptos (ideología, memoria discursiva, interdiscurso e intradiscurso) propios de la tradición francesa de análisis del discurso. Estos conceptos, especialmente el de memoria, se aplican a lo que se denomina "discours sécuritaire-identitaire", un tipo de discurso que seria propio de la derecha francesa, desde Jean-Marie Le Pen a Nicolas Sarkozy, y estaría centrado principalmente en el fenómeno de la inmigración. Así, el autor nos muestra algunos fundamentos del análisis del discurso "a la francesa" que, hasta donde yo soy capaz de ver, guarda semejanzas metodológicas y temáticas con el Análisis Crítico del Discurso. ${ }^{4}$

\footnotetext{
2 John Searle, Speech acts: an essay in the philosophy of language (Cambridge University Press: Cambridge, 1969).

${ }^{3}$ Quentin Skinner, Visions of politics, vol. 1: regarding method (Cambridge University Press: Cambridge, 2002), 114-116.

${ }^{4}$ Norman Fairclough, Analysing discourse: textual analysis for social research (Routledge: Londres, 2003); e Isabela Fairclough y Norman Fairclough, Political discourse analysis (Routledge: Oxford, 2012).
} 
La segunda sección está dedicada al concepto de Espacios. Con siete aportaciones, se aborda el problema del colonialismo y el conocimiento (Claudio Canaparo); la escultura fueneraria gótica (Sonia Morales); la espacialidad en las fortalezas medievales (Carlos J. Galbán) o la Geopolítica (Heike Pintor Pirzkall), entre otros. Quizá la aportación más destacada es la del profesor Canaparo, "El colonialismo en segundo grado. Epistemología y pensamiento periférico. Programa sobre un seminario futuro", donde el autor desarrolla, a partir de la noción de "geo-epistemología", la relación de una serie de cuestiones como la conciencia, la técnica o la "condición cinematográfica" con los "espacios periféricos". La geo-epistemología, noción acuñada por el propio autor, consiste en reflexionar sobre estos espacios periféricos teniendo en cuenta el dominio de una noción de temporalidad lineal y universal, la falta de atención al "lenguaje como elemento fundamental de la especulación" (p. 219) y la existencia de un colonialismo "de segundo grado", relacionado especialmente con el "contexto tecnológico en que el conocimiento se desarrolla" (p. 220). Sumando a todo esto una perspectiva constructivista radical (Piaget), el autor se propone "ver cómo ciertas ideas, cierta evolución del pensamiento y de los conceptos funcionan y trabajan en lugares que en su origen no fueron pensados para desarrollarse como tales" (p. 221).

Al margen del acuerdo o desacuerdo con las tesis del autor (algo que superaría con creces mis capacidades y conocimientos), me parece que este es un texto ejemplar dentro del objetivo del libro: la creación de espacios interdisplinares a través de la reflexión sobre aquellos conceptos o temáticas primigenias que ya mencioné. No solo porque se haga una aproximación, desde la filosofía aplicada al concepto de "Espacio", sino por que se hace recurriendo a otros conceptos que bien podríamos considerar como situados en ese espacio primigenio de reflexión. Es el caso de la idea de conciencia, una noción fundamental en las humanidades (y seguramente también en las ciencias sociales) sobre la que no se reflexiona lo suficiente. Así, se muestra la evolución del concepto de conciencia, a través dos momentos - aparición y crítica del concepto- y se exponen diferentes aproximaciones a la noción de conciencia (clásica, fenomenológica, post-kantiana). Esto, sumado a las reflexiones sobre la técnica y el planteamiento de la "condición cinematográfica" (que no se refiere únicamente al cine sino a una formación de la percepción a través de una tecnología visual, según alcanzo a entender) dan lugar a un texto sobre el que vale la pena reflexionar.

A continuación tenemos el apartado dedicado a la noción de contexto, de nuevo muy variada temáticamente. Se abordan, por ejemplo, problemáticas como la representación del Holocausto (Aitor M. Bolaños de Miguel); el arte en Santiago de Compostela durante la Restauración (Margarita Barral Martínez); los contextos de la obra de Raúl Glaber (Israel Sanmartín) o la sacropolítica de Otón III (Jose Ángel Salgado Loureiro), desde disciplinas y corrientes como la historiografía, la historia de las mujeres, la sociolingüística, o la historia de la música. Como decíamos, el eje articulatorio de esta sección es el concepto de Contexto. Desde ahí, Israel Sanmartín ("Temporalidades y contextos en la historiografía del siglo XI a partir de Raúl Glaber"), disecciona el texto de Raúl Glaber, Historias del primer milenio, situándolo en sus contextos histórico e historiográfico y explicando las temporalidades "ciclolineal" y escatológica de la obra, en la que tiene una especial importancia lo maravilloso y lo real 
en sus diferentes aspectos. ${ }^{5}$ Destaca lo "maravilloso-completivo", que para el autor es una búsqueda de "espacios de compensación de la dura cotidianiedad medieval, así como para ejercer la crítica al mundo y a la Iglesia del momento" (p. 336). En otra temática muy diferente, Marina Krylyschin ("Les contextes extralinguistiques de l'exposition Renoir au XXe siècle [Grand Palais, 2009]") hace una aproximación lingüística a una exposición artística, a través principalmente del concepto de contexto(s) extralinguiístico(s). Esta noción se referiría a los elementos que completan un enunciado, así como a los lugares de los que provienen estos enunciados (p. 437). Esta aproximación llevaría a estudiar las representaciones de los visitantes sobre las obras de la exposición, representaciones muy marcadas por los textos que acompañan a cada cuadro (p. 451).

Lo político tiene un importante peso en la sección dedicada a la Imagen. Tres de las aportaciones lidian con la relación entre imagen y nacionalismo, a través de los casos de Alsacia y Bretaña (José Antonio Rubio) los discursos de la Unión Liberal (Juan Antonio Inarejos Muñoz) y la iconografía postal española (Fernando Monroy-Avella). Este último recorre brevemente las representaciones ideológicas de los sellos a través de una metodología serial adaptada de la propuesta por el medievalista Jérôme Baschet. ${ }^{6} \mathrm{El}$ autor destaca cómo los sellos actúan como propagadaros de un "pensamiento oficial" que va cambiando en diferentes momentos de la historia de España. Por otro lado, Alfonso Pinilla García ("Uso y abuso de la imagen en los trabajos de historia") advierte de los peligros de la imagen como instrumento de manipulación. Para el autor, "la escasa capacidad de-codificadora que el receptor necesita para acceder y comprender una imagen muestra la superficialidad de este recurso" (p. 547). Alfonso Pinilla llama a la elaboración de una hermeneútica de la imagen y, a partir de fotografías de la historia de España de los últimos 40 años, nos muestra los múltiples significados que puede tener una imagen, reflexionando por el camino sobre la relación entre imagen, contexto, memoria, metáfora, o la interacción entre fotografía y titular en la prensa. Sobre la fotografía versa también la aportación de Claudia Polledri ("Temporalités et Contextes photographiques. Parcours entre l'art et l'histoire"), advirtiendo de que la imagen fotográfica provoca una suerte de "efecto de lo real" que lleva a reforzar la autoridad de todas las imágenes, pero también se pone sobre la mesa como en los manuales de historia existe una subordinación de la imagen al texto.

Las dos últimas secciones están dedicadas a la Escritura y al Tiempo, con siete y cinco contribuciones respectivamente, de nuevo con amplia variedad temática, desde una reflexión teórica sobre la escritura (Iulian Popescu) hasta un enfoque cognitivosemático sobre el tiempo en Shakespeare (Adina Oana Nicolae); pasando también por la escritura sobre el arte agentino en los sesenta (Berenice Gustavino); la reflexión lingüística sobre la expresión de frecuencia (Mioara Adelina Angheluta); la obra de Flaubert (Diana Rînciog); las escenificaciones del pasado y los medios audiovisuales (Juan Andrés Bresciano); o la música el tiempo y el espacio en la Edad Media (Isis Gradín Fernández).

La aportación de Iulian Popescu ("Prolégomènes à une esthétique de l'écriture")

\footnotetext{
5 Sobre el concepto de maravilloso en la Edad Media, véase Jacques Le Goff, Lo maravilloso y lo cotidiano en el Occidente medieval (Gedisa: Barcelona, 1985).

${ }^{6}$ Véase Jêróme Saschet, L’iconographie médiéval (Gallimard: París, 2008).
} 
resulta especialmente ambiciosa, ya que se propone construir una estética de la escritura, en paralelo a la estética de la recepción. A partir de autores como Fernand Braudel, Thomas Kuhn y Egar Morin, el autor se propone superar la distinción habitual entre "corrientes" (Edad Media, Renacimiento, Clasicismo, Romanticismo, Realismo, etc) de la historia literaria, ya que esta estaría demasiado fundamentada en la estructura narrativa. Frente a esto, se propone una división entre dos paradigmas: el clásico, fundamentado en el orden, y el moderno, que sería el paradigma del desorden. Así, en el paradigma clásico la literatura se concebiría como un espejo de la realidad, en la que primarían nociones como orden, mesura, equilibrio, simetría o harmonia (p. 671). Por contra, en el paradigma moderno "le suje et l'objet de la connaissance s'autodéterminent dans une pratique cognitive qui les rend inséparables" (p. 673), dando lugar a una "écriture du discontinu" (p. 675), caracterizada por la ruptura y por el desorden.

En otro orden, la contribución de Isis Gradín ("Las relaciones entre música y tiempo en el Tractatus de Jerónimo de Moravia") combina teoría musical e historia medieval, analizando el Tractatus de Musica, de Jerónimo de Moravia, un texto del siglo XIII. La autora no solo identifica diferentes temporalidades en el texto y contexto (tiempo lineal, tiempo cíclico y universo, tiempo y memoria), sino que defiende de manera fundamentada lo que parece ser una posición heterodoxa dentro de la teoría musical: la espacialidad de la música. A través de conceptos como simultaneidad (las diferentes voces que suenan al mismo tiempo), "espacio tonal" y "textura musical", y apoyada por las reflexiones de Jerónimo Moravia, I. Gradín argumenta que el "espacio también está presente en la música". Estas reflexiones encajan a la perfección con los objetivos del volumen, al plantearse el Espacio, junto a la temporalidad, como uno de esos conceptos primigenios compartidos por las disciplinas humanísticas, en este caso la historia medieval.

Sin duda, uno de las mayores virtudes de la obra es su extensa variedad, tanto temática como metodológica. La cantidad de temas que se presentan al lector ayudan a salir de los esquemas de especialización extrema propia de la academia actual. Asimismo, el abordaje teórico a conceptos como discurso o contexto supone un desafío (y un descubrimiento, a menudo) para los que estamos interesados en la intersección entre teoria y práctica. Ahora bien, también se podría decir que, producto de esta variedad, viene su vicio principal, la irregularidad de las aportaciones, ya que hay una importante desigualdad en la profundidad intelectual de los capítulos y, en ciertas ocasiones resulta complicado ver el enlace con los objetivos que se proponen los editores, es decir, la reflexión sobre las temáticas fundamentales de diversas disciplinas. Sea como fuere, este no es un defecto demasiado grave en un libro colectivo de más de 800 páginas.

Roque Sampedro López

Universidad de Santiago de Compostela

roquesampedro@gmail.com 
Fecha de recepción: 12 de junio de 2018.

Fecha de aceptación: 16 de julio de 2018.

Publicación: 31 de diciembre de 2018.

Para citar este artículo: Roque Sampedro López, "Israel Sanmartín y Sonia GómezJordana, Temporalidad y contextos. La interdisciplinariedad a partir de la historia, el arte y la lingüística. Universidade de Santiago de Compostela: Santiago de Compostela, 2015, 815 págs.”, Historiografías, 16 (julio-diciembre, 2018): 142-147. 